\title{
The Design of Supply Chain Logistics Information Integration Platform for Auto Parts Enterprises Based on Multi-agent
}

\author{
Ming $\mathrm{Li}^{1, \mathrm{a}}$, Xiao-Ning Fang ${ }^{2, \mathrm{~b},{ }^{*}, \text { Chang-Chun Jiang }}{ }^{3, \mathrm{c}}$ \\ ${ }^{1}$ School of Management, Guangxi University of Science and Technology, Liu Zhou, Guang Xi P.R. \\ China, 545006 \\ ${ }^{2} 2011$ levels of information management and information system, School of Management, Guangxi \\ University of Science and Technology, Liu Zhou, Guang Xi P.R. China, 545006 \\ ${ }^{3}$ Wuhan ZhiMing Information Co., Ltd, Wuhan, Hubei P.R. China, 43007 \\ awuqingmingjian@qq.com, b18677294219@163.com, cjiangchangchun@zmit.com \\ ${ }^{*}$ Corresponding author
}

Keywords: Auto parts enterprise, Supply chain, Multi-agent, Logistics information integration platform.

\begin{abstract}
Starting from the auto parts manufacturers operating target, the use Internet of Things technology, reasonable technology, management of engineering technology, computer network technology, bar code automatic identification technology, artificial intelligence technology, agent technology, lean production, agile manufacturing and the advanced concepts, close combined with the actual situation of enterprises. Integrate the information to establish practical, reliable, shared, complete, advanced, with some cost-effective agile supply chain logistics information integration system. Enables companies to quickly produce, real-time tracking of production information, understand the production status, to provide reliable information for the entire firm's business operation, ensure the auto spare parts and timely delivery of products, improve the company's market competition ability.
\end{abstract}

\section{Introduction}

In 2012, the domestic auto market is an interesting phenomenon: auto parts manufacturers' generally substantial growth in corporate profits, but carmakers profits than ever decline. Expected in the next few years, the use of IT systems management and control logistics business sectors will be the focus of auto parts manufacturing enterprise. Auto parts enterprises based on logistics information integration platform for networking and other technology can significantly enhance the core competitiveness of enterprises, shortening enterprise product manufacturing cycle, strengthen enterprise product data security, through to enterprise logistics business process and project visualization able to optimize logistics management processes, reduce logistics and the flow of information in error, extending the project to monitor radius. Therefore, building-based auto parts supply chain logistics information network integration platform, is a powerful guarantee to meet the challenges of the twenty-first century market.

\section{Comparative Analysis of Domestic and Foreign Enterprises Logistics Information}

According to Analysis International Research, in 2012 domestic auto parts manufacturing enterprise logistics information construction market is 1.226 billion Yuan. Joint ventures are the investment subject and application demonstration benchmarking industry logistics informatization construction of domestic auto parts manufacturing. Its logistics informatization construction is large and persistent pursuit of rapid construction, with relatively high logistics informatization investment return for the core management ability. The main software system used by the joint venture and important hardware system selection and more foreign factories abroad reference system configuration, and in the construction of a new plant before the comprehensive plan. System implementation method basically rely on foreign strong, according to the system process to promote 
enterprise flow construction and transformation. According to the enterprise management of the different background, the construction of logistics informatization strategy there are differences.

Germany, US funded enterprises pay attention to the stability of the system, comprehensive. A small number of systems, a single system fully functional, logistics informationization construction of a great input. For the emerging IT technology, enterprise dare to introduce and try to apply.

Japanese, Korean enterprises to focus on the effectiveness and input-output system. The large number of system, single system function is more specific, more integrated demand system, need to operate the employees have a sense of responsibility. Enterprise are very cautious to the emerging IT technology, multiple use of the mature IT technology.

Venture-funded enterprises to learn from the joint venture enterprise logistics informatization construction thinking method and IT system. However, due in 2010, 2011 years of domestic enterprises generally poor economic benefit, its recent logistics informatization construction is also more cautious investment. In the IT system implementation, but also more need to accommodate the status quo of the enterprise. Domestic enterprises according to their own situation and needs for enterprise application level configuration of IT system itself.

\section{Overview of Supply chain Logistics Information Integration Platform}

Logistics information of automobile spare parts supply chain integration platform for networking and intelligent based on multi agent technology is a system connecting base MES and high-level ERP integrated platform of auto parts manufacturers according to their own actual situation specially developed. Automobile spare parts supply chain logistics information integration platform through the business process management and information resource sharing component middleware layer. On the one hand, through information integration, horizontal and vertical integration between enterprise each application system, provide the open software interface, making all kinds of application development and application of interactive collaborative operation can make information through this platform, various underlying system not only can be compatible with the existing auto parts enterprises, and open architecture that can be extended, hanging pick up some generic extension system, at the same time, provides data management and data communication services, access and application support information in distributed environment implementation. On the other hand, through process management, the realization enterprise management business process modeling, process planning, process execution, process monitoring, and finally realize the integration of the enterprise. The three layer of enterprise application integration platform based on XML data transfer-company. Through the establishment of three layers of enterprise application integration platform based on XML data transmission, realize the integration of enterprise internal and external information system, which makes the initial host plant with the supply chain management mode implementation; to achieve synergy in design, production and management. Finally to supply chain logistics information of car parts integrated platform based, integrated manufacturing management system, in order to extend to the sales and purchase link, and the capital flow integration, and ultimately the formation of the auto parts industry intelligent highly integrated information solutions.

\section{Intelligent Multi-Agent Technology Overview}

\section{Overview of Intelligent Agent Technology}

Intelligent agent technology is an application of artificial intelligence technology that enables computer applications tend humane and personalized. Intelligent agents are considered to be in a certain environment Agent can continue to play a role independently, with computing entity lifecycle. Autonomous, community, reactivity, initiative, rationality, learning and adaptability, reasoning ability and other characteristics. Agent is often the user interface module, learning module, task technology module, operating system interface module, execution module, a knowledge base and a central control module. The central control module are the core of the Agent, in control of all the other modules. 


\section{Multi-agent Technology Overview}

Multi agent system (multi-agent) is a kind of intelligent and flexible response to system changes to working conditions and the surrounding process demand. Multi agent system is composed of a plurality of agent through mutual cooperation, the basic unit is the agent, and agent can interact with its host environment. The agent is composed of 3 functional layers: management and organization layer, coordination layer and execution layer. Management and organization layer is obtained mainly target definition or question, as well as the constraint conditions, including the implementation of the plan, function evaluation and learning. The coordination layer task is according to the basic process from management and organization layer definition, action steps to activate the action execution; coordination layer can be extended to action, so in response to events. The execution layer is a series of action execution, and follow on action check.

\section{Intelligent Multi-agent Technology Auto Parts Supply Chain Logistics Information Integration Platform-based Design}

\section{The Design Goal of Integration Platform of Auto Parts Enterprises of Supply Chain Logistics Information.}

Automobile parts enterprise supply chain logistics information integration platform refers to the construction and development of the supply chain logistics of automobile parts enterprises, in the areas of raw material procurement, spare parts production and logistics management, making full use of information communication technology, the wisdom perception, analysis, to be cooperative in the agile manufacturing and lean logistics activities in the demand of enterprise at the same time it can cooperate, develop the manufacturing services, to create a safe and efficient supply chain logistics system. Integrated supply chain logistics information platform is a include information management system from the procurement management, inventory management, production management, distribution management and bar code tracking function etc.. Through the research of the information integration platform, the construction of enterprise into the factory and the factory logistics management system, implementation of workshop material order decomposition tasks, the formation of bill of material, and to the workshop material field distribution and the use of materials for the implementation of state monitoring, improve the rational configuration of real-time and workshop production line of the mixed material distribution, reduces the enterprise the the inventory cost, solve the low production line configuration problem of mixed ability. To increase the height of the integration of enterprise internal and external information, can quickly and timely tracking production information, understand the production status, and provide reliable information for the entire firm management operation, to achieve a high degree of intelligence and information. At the same time, along with the deepening of production information utilization will inevitably bring about the requirements for production information with improvement, the system must have a certain ability to adapt to such changes, and the demand of supply chain logistics information integration platform must have sufficient capacity expansion.

\section{Thinking of Construction Platform}

In accordance with the "overall planning, step-by-step implementation, key breakthrough, benefits" principle, the formulation and implementation of strategy and the concrete application scheme for supply chain logistics information integration platform based on Internet of things technology and intelligent multi agent. First built in the logistics business enterprises of auto parts supply chain model based on customer customization, form a kind of the service oriented architecture based on component, in particular the development and implementation process step by step, the implementation of phase; focus on the development process of the system, closely combined with the actual needs of enterprises, to maximize the compatible with its existing work model, to solve the most urgent problems for the enterprise; in the system implementation process based on a full line of business and divided the implementation phase, according to business problems urgent degree and important degree, from easy to difficult, from the inside out, the 
implementation of the system on to the surface. System integration platform to establish the digital, intelligent, integrated, open a business oriented associated enterprises, high efficient management of logistics enterprises to achieve internal and external, to achieve inter enterprise rapid response and collaborative management, increase the enterprise's strain capacity and competitiveness.

Including the establishment of three levels, the system framework of application layer, middleware layer and system integration platform. The composition of the middleware layer system integration platform through the sharing of business process management and information resources. On the one hand, through information integration, horizontal and vertical contact established between supply chain enterprises of various application systems, provide open software interface, making all kinds of application development and application of interactive collaborative operation, can carry out the logistics information through the platform at the same time, provides data management and data communication services, access and applications to support logistics information distribution in the environment of execution. On the other hand, through process management, to achieve inter enterprise logistics business modeling, logistics process planning, logistics process execution, logistics process monitoring, and finally realize the integration of enterprise logistics information system.

\section{The Main Functions of the Platform}

Inbound logistics agent: through the purchase price maintenance, purchasing plan, purchase order generation, to achieve the procurement warehousing management, solve the logistics to manage material storage and sent to the production line. Including: acceptance, storage quality inspection (including return), position management, custody, issuing to production line.

Plant logistics agency: draw up production plan, set up production plan, through the logistics management platform is highly intelligent, solve the problem of plant distribution in the distribution of raw materials and components, can optimize the management plan according to the market demand, meet the workshop plan business needs, and to achieve the release plan of Web pages.

The leaving factory logistics agency: through the inventory management and distribution management of automobile parts, realize the integration and docking business and information of the host plant, the host plant to solve the multi frequency and small batch orders.

Tracing agent quality management and product: the product traceability system to meet the relevant quality business functions, the system can also be configured flexibly.

Supply chain bar code tracking agent: parts of the production process of each point can be real-time input or scanning parts information and quality information; each point can record information logistics and manufacturing process.

Interface platform agent: the need to establish a unified platform for the application interface, can provide the downstream and upstream of the system data interface system, ensure the information sharing.

Production report agency: report display mode with WEB pages, including the related management aspects related to logistics and distribution process, the process of manufacturing various types of reports.

\section{The Important Significance of the Platform}

The main strategy of automobile spare parts supply chain logistics information integration platform is a large dynamic range of integration, the integration to improve the procurement, production and sales of enterprise management to a higher stage of development. That is to say the intelligent integrated platform includes some major advanced manufacturing technologies such as the Internet of things technology, the development of data exchange standard, process reengineering, enterprise resource planning, management system and technology, e-commerce technology, and these advanced manufacturing technology is the auto parts manufacturing enterprises in the face of the twenty-first Century global competitive enabler. Specifically, the project has the following practical significance to the economic development of our country. 
First, to provide a new ideas for the development of car manufacturing enterprise group it is the structure of industry of our country automobile reorganization, automobile and parts manufacturing enterprises, reform. Help manufacturing enterprises to break the compartmentalization, realize the joint cross sectorial, cross industry, cross regional. Advocated by the automobile manufacturing enterprises reduced functionality, the use of external resources, help to overcome the "big and complete, defects of small and complete", the promotion of social specialization division of labor.

Second, it is conducive to China's automobile industry to improve the competitive advantage in the international competition. Automobile spare parts supply chain logistics information integration platform allows Multi-National Corporation looking for partners in the global scope, the production cost is reduced, which means there are more opportunities of China's automobile industry.

Third, to our country auto parts manufacturing enterprise that guide the development of enterprises in the new century the management ideology, organization form, operation mode. First of all, automobile spare parts supply chain logistics information integration platform embodies the decentralized management, people management, flexible management, strategic management, management thought, to our country automobile industry in the micro management of the information age has an important reference significance.

\section{Summary}

Logistics information auto supply chain integration platform can effectively plan and monitor the auto parts procurement, production, and distribution of the various links; so that the company can fast, real-time tracking of logistics information, understand the logistics status, provide reliable information for the entire firm's business operation, ensure the auto spare parts and timely delivery of products, improve the company's market competition ability. The proposed model and method is suitable for the logistics information system in China's auto parts enterprises integration and management, and the research and Realization of auto parts enterprises integrated logistics information platform, is of great significance to the application field of auto parts enterprises logistics management and control, logistics research.

\section{Acknowledgement}

This research was financially supported by Guangxi autonomous region level and the National college students' innovation and entrepreneurship training plan project: "Research on supply chain logistics information integration and innovation of intelligent multi-agent system based on auto parts enterprises" (Guangxi autonomous region level project number: 201410594088), (National project number: 201410594036)

\section{References}

[1] Peng Junsong, The automobile industry supply chain strategy, management and information system, electronic machinery industry press, Beijing, 2005,pp.167-214.

[2] Duwen Jia, Logistics Management Based on information technology supply chain Managers. 2010, pp.75-89.

[3] Fan Zhang sister Xiamen University, based on supply chain cost management agency theory. 2008, pp. 281-304.

[4] DIMEASAL, HATZI ARGYRIOUND. Agent based Control for Micro grids. Power Engineering Society General Meeting. IEEE. 2007, pp.213-295.

[5] Robert R. Inman, Dennis E. Blumenfeld. Product complexity and supply chain design. International Journal of Production Research, 2014, pp.137-151. 